\title{
REAL CONVERGENCE OF BOSNIA AND HERZEGOVINA TOWARDS THE EUROPEAN UNION
}

\section{Hasan Mahmutović ${ }^{1}$ Alem Merdić}

University of Zenica, Faculty of Economics, Bosnia and Herzegovina

\author{
Original scientific paper \\ DOI:10.21554/hrr.091706
}

Received: 18.07.2017

Accepted: 28.08.2017

\begin{abstract}
The entire process of Bosnia and Herzegovina's path to European integration so far, is mostly limited to the problems of achieving political consensus, neglecting the essence and purpose of the integration process, which is primarily reflected in achieving the real convergence of Bosnia and Herzegovina towards the EU. The absence of real convergence, and adequate preparation in terms of competitiveness of the economy of Bosnia and Herzegovina for the EU membership, can cause negative effects of integration. Considering that there has not yet been written any paper that questions the lack of real convergence, primarily GDP p.c., and that a complete analysis of economic criteria is reduced to the Progress Reports of Bosnia and Herzegovina towards the EU, which summarize the fulfilment of the economic criteria of Bosnia and Herzegovina for the EU membership without concrete suggestions for improvement, this paper analyzes the real convergence of Bosnia and Herzegovina towards the European Union, observed through the income level p.c., prices and productivity of the labor force. The analysis showed that there is a sigma convergence of Bosnia and Herzegovina towards the EU in the movement of GDP p.c., which is reflected in the reduction of the coefficient of variation of the observed parameter in the period from 2000 to 2015 from $89.8 \%$ to $85.3 \%$, which is a decrease in the coefficient of variation for 4, 5 p.p. for 16 years.In the observed period there was an increase in the absolute GDP p.c. gap, which means that Bosnia and Herzegovina must increase the rate of economic growth in the coming period, in order to stop the relative decrease in the standard of living in relation to the EU.In addition, the analysis of sigma convergence has shown that there are sigma divergent trends in the movement of productivity and price level of Bosnia and Herzegovina in relation to productivity and price level at the EU level.It is expected that the price level in Bosnia and Herzegovina will increase in the coming period as a result of the activation of the Stabilization and Association Agreement and a higher degree of trade integration with the EU.
\end{abstract}

Keywords: real convergence, Bosnia and Herzegovina, GDP p.c., productivity, price level. JEL: F 15; F 43

\section{INTRODUCTION}

The purpose of implementing the process of a nominal convention towards the EU, observed through the meeting of the Copenhagen and Maastricht criteria, is to achieve a real convergence, which involves converging the economic parameters of the participants in the convergence process, in order to reduce regional differences in the degree of development, and to make a equitable distribution of wealth.In order to achieve real convergence, it is necessary to provide institutional convergence, but also a similarity of economic structures, which will enable the creation of a complete development infrastructure by the convergence of the countries, involved and, based on that, reach a real convergence.

\footnotetext{
$\overline{{ }^{1} \text { Correspodence to: }}$

Hasan Mahmutović, PhD, University of Zenica, Faculty of Economics, Bosnia and Herzegovina

Phone: +387 61912531

E-mail: hasanmahmutovic@hotmail.com
} 
However, the analysis of real convergence needs to be approached analytically both by territorial and economic criteria. The analytical approach to real convergence implies that an analysis needs to be made according to each of the criteria of real convergence, which should show the following: the achieved level of convergence, the factors that limit the convergence, or cause divergent movements, and the preparation of the action plan of economic policy measures for the improvement of the convergence process, monitoring the implementation of planned activities and timely implementation of corrective actions in case of significant deviations.Less developed countries in a tendency to reach acceptable level of competitiveness, and real convergence, in relation to developed countries, can often cause intraregional divergent trends, which include the creation of differences in development within different regions of a country, and thus are in the trade-off situation between international convergence and interregional divergence (more details: Hallet, 2002, Marelli, 2007). Of course, it is much easier to solve the problem of intraregional divergence in relation to international divergent movements, since the authorities within their own country control economic instruments, and in this way they can work towards reducing differences in regional (in) development, if that is their goal, while in the case of international convergence coordination of economic activities with the convergence of the countries involved is required. An important aspect of real convergence is certainly convergence in the performance of the labor market, given that GDP per capita, as the best representative of real convergence, depends on the labor market trends, i.e. the convergence / divergence of these markets and trends in the unemployment rates of the observed countries.

Regarding the transition countries which are in the process of joining the European Union, a significant factor in the process of real convergence is the completion of the process of transition of the business system, in order to provide all the necessary conditions for economic activity at the level of the developed industrial countries, thus creating the basis for realization of real convergence. The real convergence of these countries depends on many specific factors, such as the avoidance of macroeconomic crises, the development of the financial sector, high investment rates and many others (Bilas, 2005).

It is important to emphasize that the lack of real convergence and the adequate preparation for the competitiveness of the economy of Bosnia and Herzegovina for EU membership can cause the negative effects of integration and that the level of benefits that will be achieved through integration in the EU depends on the degree of real convergence of Bosnia and Herzegovina towards the EU.Therefore, this paper analyzes the real convergence of Bosnia and Herzegovina towards the EU in order to point out the chaotic situation of the economy of Bosnia and Herzegovina, and to draw attention to the need for an offensive approach to meeting the economic convergence criteria.Real convergence, in this paper, is analyzed using the sigma convergence through 3 criteria: the level of GDP p.c., the price level and productivity of Bosnia and Herzegovina compared to the value of these parameters at the EU level.

\section{A THEORETICAL REVIEW ON REAL CONVER- GENCE AND THE METHODOLOGY OF RE- SEARCH}

\section{The criteria of real convergence}

The criteria of real convergence reduce the mutual convergence of the following economic parameters between the observed countries: GDP p.c.level, level of nominal wages, real exchange rate equilibrium, price level, level of productivity.These criteria are analyzed in relation to the developed countries, and in the context of European integration, in relation to the average value of the individual criteria at the level of the European Union.However, it is not uncommon for cyclical economic trends to have certain divergent trends that only prolong the period of real convergence, all of which means that the convergence process can not be easily controlled, because of systemic risks, or there is no corresponding level of readiness of developed economies, bearers of European integrations, to realize a process of real convergence. For the convergence of each of these variables, a longer period of time is required which should be the result of structural and institutional convergences, and in particular the result of a successful nominal convergence that will create a functioning market economy and an economy strong enough to deal with competitive forces within the European Union. Also, in order to accelerate the process of real convergence, trade integration between candidate countries and potential EU member states with EU members is particularly important, which could intensify the cooperation from which other positive effects could contribute to the process of real convergence, such as transfer of technology and FDI from developed countries to less developed countries, but all in the context of macroeconomic stability and economic competitiveness for ease of doing business (according to reports by international financial institutions, egDoeing Business - World Bank Report). 


\section{Nominal vs. Real convergence}

In the previous text about the problem of nominal and real convergence, it was emphasized that the goal of implementing nominal convergence is the realization of real convergence. Therefore, this would mean that first it is necessary to meet the criteria of nominal convergence, in order to ultimately have the approximation of the standard of living of the participating countries in the convergence process as a final result.The ratio of nominal and real convergence can be twofold, i.e. nominal convergence can lead to real convergence, and real convergence can support the realization of nominal convergence in certain segments, on the one hand, while, on the other hand, a conflict can occur in the pursuit of simultaneous achievement of the real and nominal convergence.

Meeting the nominal convergence criteria contributes to real convergence in the following:

a)Meeting the price stability criteria and achieving fiscal discipline positively affects the stabilization of overall macroeconomic conditions, which positively influences the decline in interest rates (Bilas, 2005).The decline in interest rates implies cheaper funds, which, at the net present value, as one of the methods of estimating the efficiency of investments, implies a greater number of projects with a positive net present value.A larger number of positive NPV projects (net present value) means a greater number of cost-effective projects that will be realized, and this ultimately involves greater investment, which leads to employment growth and total production, which is the goal of real convergence.

b)Realizing the stability of the exchange rate, as one of the criteria of nominal convergence, contributes to the reduction of foreign exchange risk in international business, which positively influences the strengthening of export activity, which, again, positively reflects on the total volume of production, i.e. GDP p.c. growth, ceteris paribus .

The realization of real convergence, primarily the growth of gross domestic product, contributes to meeting the criteria of nominal convergence.Economic growth creates the basis for increasing wages, but without inflation, and contributes to fiscal consolidation, since, only in the case of an efficient state apparatus and financial control authorities, the budget side is increasing, which positively influences the decline of the budget deficit and reduces the need for more intensive public borrowing.
As stated above, nominal and real convergence can mutually contribute to achieving the goals of both, but they can also end up in a conflict. The confrontation of nominal and real convergence is reflected in the following (Gaspar, 2001):

- Higher inflation rates are usually associated with higher growth rates;

- The expectation of price convergence and future membership in the monetary union can lead to a decline in long-term interest rates, but short-term converge gradually, reflecting macroeconomic instability and risks in transition countries. This can result in higher nominal interest rates over a longer period; the inability to simultaneously meet the criteria of the exchange rate and inflation. Considering the link between prices and the exchange rate with output, this would mean again a conflict of real and nominal convergence;

- The objective of exchange rate stability can lead to an unsustainable current account balance if it is fixed at an inappropriate level (imbalanced);

- The objective of real convergence - achieving a higher degree of productivity can cause inflation ${ }^{2}$;

- Rapid GDP growth, capital inflows and fiscal consolidation can lead to a slowdown in the convergence of interest rates, as high interest rates will be needed to increase domestic savings in order to reduce the reliance on foreign savings and current account vulnerability and

- Capital inflows, a high real and financial openness can lead to the volatility of the nominal exchange rate.

\section{METHODOLOGY OF RESEARCH}

For the analysis of real convergence, sigma convergence will be used which implies decreasing the dispersion of the observed variable over time, and as a measure the coefficient of variation of the given variable over time is used, and if there is a decrease in the observed variation coefficient among the observed group of countries then it can be said that there is a sigma convergence among the observed countries, and otherwise there is sigma divergence. Sigma convergence exists if:

$\sigma_{t+n}<\sigma_{t}$

Sigma Convergence is a concept by which it is examined whether the differences between regions measured by income per capita, or some other parameter, are reduced over time.

$\overline{{ }^{2} \text { Balassa }- \text { Samuelson effect }}$ 


\section{RESULTS}

As stated in the theoretical coverage of real convergence, real convergence, in the context of European integration, implies bringing the value of economic parameters, primarily GDP p.c., to the average values of these parameters at the EU level.Particular emphasis in this section will be put on the income convergence, in order to determine whether per capita income in Bosnia and Herzegovina is approaching the EU average, ie whether there are convergent or divergent movements, and how to accelerate the process of income convergence.In addition to GDP p.c., the convergence of productivity and price levels of Bosnia and Herzegovina against the same EU indicators will be analyzed.Analysis of the convergence of these variables according to the same at the EU level will be carried out using the sigma convergence. Sigma con- vergence implies reducing the dispersion of observed variables over time between the observed territories, that is, the analysis of the movement of regional differences through observed economic variables (divergence or convergence).

Chart 1 shows the variation coefficient movement of GDP p.c. of Bosnia and Herzegovina towards the average GDP p.c. of the EU - 28 for the period $2000-2015$, in order to determine the existence of sigma convergence, i.e. the movement of income distribution. The dispersion of income per capita in the observed period has decreased from $89.8 \%$ to $85.3 \%$, which means that there is a sigma convergence, which also means, that the dispersion of the income of Bosnia and Herzegovina in relation to the EU-28 average is decreasing. The decrease of income dispersion is the result of a higher average growth rate in Bosnia and Herzegovina compared to the growth rate of the EU-28. ${ }^{3}$

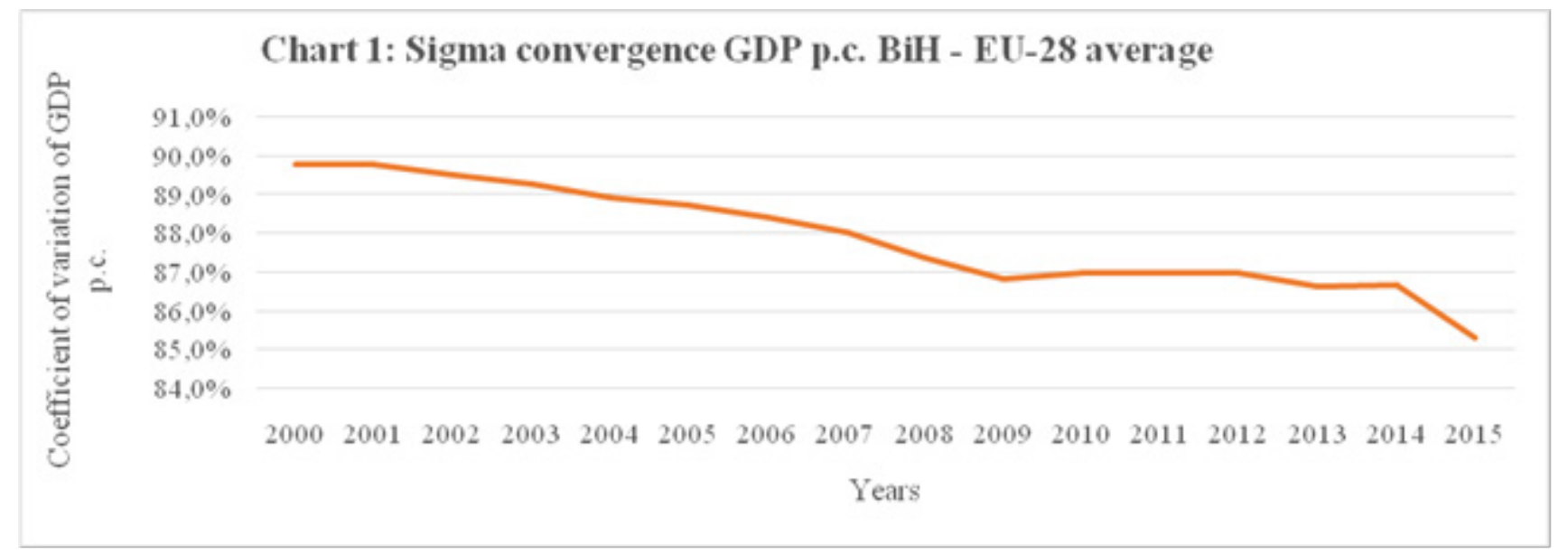

Source: authors' calculation, data: http://ec.europa.eu/eurostat; Http://data.worldbank.org (accessed 15.7.2017)

The results of the sigma convergence shown in Chart 1 should not lead us to a wrong conclusion.Namely, the dispersion of income per capita is decreasing, however, the initial average deviation is $89.8 \%$, and after 16 years, the relative average deviation of income per inhabitant of $\mathrm{B} \& \mathrm{H}$ in relation to the EU-28 average is $85.3 \%$, which indicates the slow process of decrease of the dispersion of income, i.e., the slowness in the development of sigma convergence.Considering the average higher growth rate of Bosnia and Herzegovina, and the fact that in the forthcoming period this growth rate could be decreased due to an increase in the base (GDP absolute value growth), as is the case with Croatia (whose average growth rate in the last ten-year period was $0 \%$ and the growth rate in 2015 was $1.6 \%$, which is less than the EU-28 average growth rate of $2.2 \%$ ), the question is how long the process of income convergence will take, and whether the approximation of income per capita of Bosnia and Herzegovina to the average income of the EU-28 will ever be fully realized.
It should also be noted that the sigma convergence is an indicator of relative dispersion, and that, in the observed period, the GDP p.c. gap in absolute amount has increased from 20.550 EUR / c. (2000), to 22,600 EUR / c. (2015), which means a 10\% growth in the absolute GDP gap, which means that there are divergent movements, that is, the increase in regional disproportions in per capita income.Similar economic trends in terms of real GDP p.c.also has Croatia, since from 2000 to 2015 there is a continuously positive trend of absolute GDP p.c. gap growth (in 2000 the absolute GDP p.c. gap amounted to 14,900 EUR/c. and in 2015 16,100 EUR/c).

${ }^{3}$ EU-28 in the observed period grewatan average rate $0.9 \%$, while Bosnia and Herzegovina at an averagerate of $2.9 \%$. 
Thus, Croatia has not yet reached the level of $50 \%$ GDP p.c. EU-28, and records negative developments in this regard even after EU membership, which can be a lesson for Bosnia and Herzegovina, that membership alone does not mean a growth in the standard of living. When it comes to Bosnia and Herzegovina, due to the significant deviation of GDP p.c. from the EU-28 average, it is certain that GDP p.c will grow and the coefficient of variation of per capita income will decrease, currently at $85.3 \%$, but due to the limited availability of capital and the concentration of low-cumulative economic branches and the underde- velopment of capital markets, income convergence will take a long time, and the question is whether it will ever completely happen.

A particularly significant issue of real convergence is the level of productivity, given that the level of productivity has a direct impact on the overall GDP level. Chart 2 shows the movement of the coefficient of variation, as the relative measure of dispersion, productivity of Bosnia and Herzegovina against the average productivity of the EU-28 for the period from 2000 to 2015 .

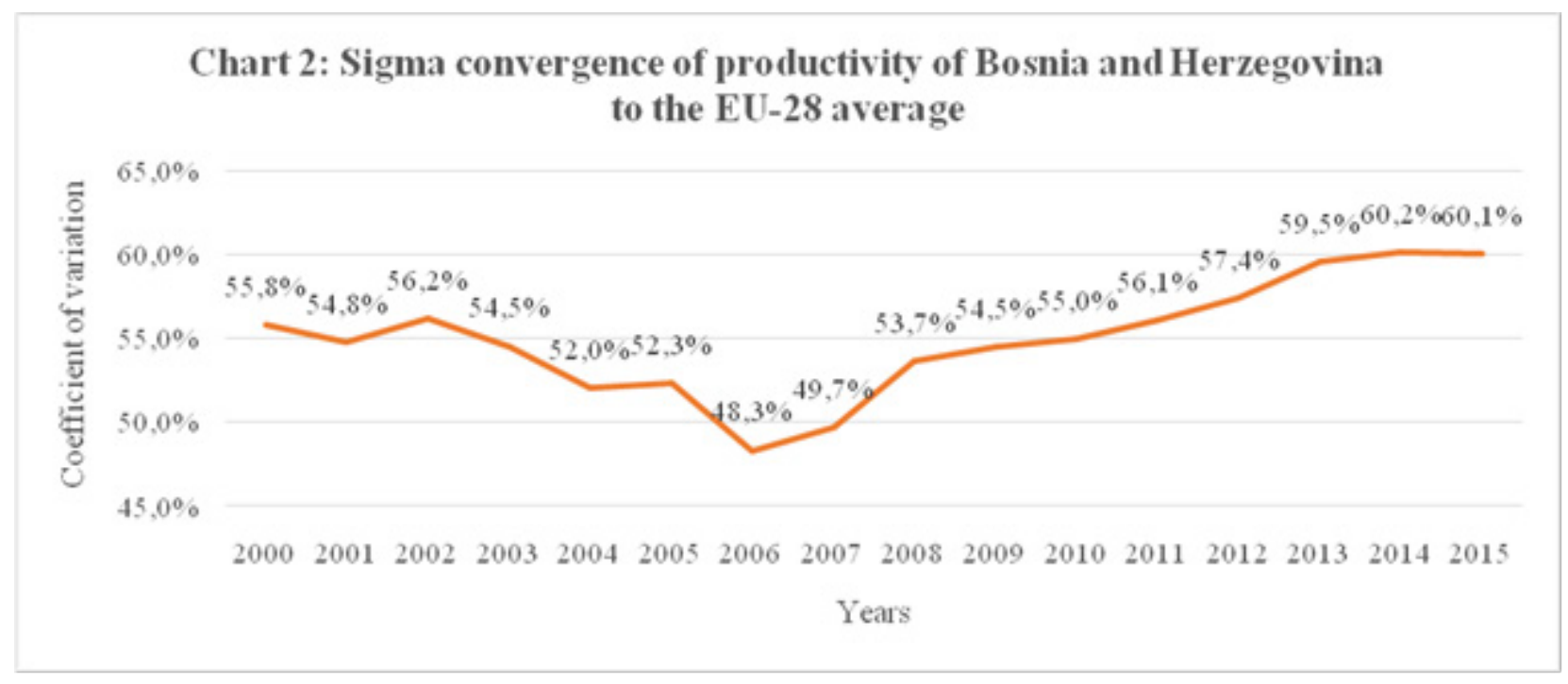

Source: author's calculation; Data: http://data.worldbank.org; Https://data.oecd.org/ (accessed: 17.7.2017)

The movement of the coefficient of variation in productivity indicates the existence of sigma convergence of productivity in the period from 2000 to 2006, when the dispersion of productivity from $55.8 \%$ to $48.3 \%$ of the EU average had decreased.Since 2007 there have been divergent movements in productivity, so that from the initial $48.3 \%$ in 2006 , the relative measure of productivity dispersion (coefficient of variation) was $60.1 \%$, indicating the existence of sigma divergence. On the one hand, the increased level of GDP p.c., and, on the other hand, the decrease in productivity indicates that the level of GDP p.c. increased thanks to the increased employment rate, but that there are declining yields to the labor force.Also, the reason for the decrease in productivity can be the reduced inflow of Foreign Direct Investment, and the lower level of technical equipment in comparison with the EU - 28 averages.In addition, reduced productivity in relation to the EU-28 average is the result of a higher percentage share of low-cumulative activity in the GDP structure, which results in a decrease in the value of output per worker (for example, in the
GDP structure of Bosnia and Herzegovina the only high-cumulative activity that has significantly contributed to the creation of GDP is the processing industry with $11.64 \%$, while wholesale and retail trade, repair of motor vehicles and motorcycles participated with $13.45 \%$, followed by public administration and defense with $8.65 \%$, agriculture, fishing and forestry with $6.23 \%$ ). The analysis of the experience of Croatia after EU membership shows that, according to the World Bank, labor productivity fell from \$ 54,253.69 in 2013 to $\$ 53,601.74$ in 2014

In order to assess the real convergence and for the very process of the accession of Bosnia and Herzegovina to the European Union, it is important to analyze price level movement in relation to the EU-28 average, in order to assess the pressure of increasing prices by the act of joining the EU common market.. Table 1 shows the average percentage deviation from the average of prices at EU-28 level of "new" EU member states (countries from the Enlargement of the EU, Romania, Bulgaria and Croatia), and Bosnia and Herzegovina. 
Table 1 Coefficient of variation of prices in Bosnia and Herzegovina and new EU member states compared to the EU-28 average

\begin{tabular}{cccccccc}
\hline Years & $\begin{array}{c}\text { Bosnia and } \\
\text { Herzegovina }\end{array}$ & $\begin{array}{c}\text { Čzech } \\
\text { Republic }\end{array}$ & Cyprus & Estonia & Hungary & Latvia & Lithuania \\
\hline $\mathbf{2 0 0 5}$ & $\mathbf{5 0 , 0} \%$ & $41,7 \%$ & $11,6 \%$ & $37,6 \%$ & $37,5 \%$ & $44,0 \%$ & $46,8 \%$ \\
$\mathbf{2 0 0 6}$ & $\mathbf{4 8 , 3 \%}$ & $37,5 \%$ & $10,6 \%$ & $33,6 \%$ & $39,9 \%$ & $37,6 \%$ & $43,7 \%$ \\
$\mathbf{2 0 0 7}$ & $\mathbf{4 7 , 9 \%}$ & $37,0 \%$ & $13,4 \%$ & $30,2 \%$ & $33,6 \%$ & $31,6 \%$ & $41,3 \%$ \\
$\mathbf{2 0 0 8}$ & $\mathbf{4 4 , 5 \%}$ & $27,7 \%$ & $11,4 \%$ & $26,3 \%$ & $31,5 \%$ & $24,4 \%$ & $35,7 \%$ \\
$\mathbf{2 0 0 9}$ & $\mathbf{4 3 , 9 \%}$ & $31,2 \%$ & $8,3 \%$ & $26,9 \%$ & $37,2 \%$ & $25,8 \%$ & $34,7 \%$ \\
$\mathbf{2 0 1 0}$ & $\mathbf{4 5 , 0 \%}$ & $28,4 \%$ & $6,7 \%$ & $28,3 \%$ & $36,6 \%$ & $31,4 \%$ & $36,9 \%$ \\
$\mathbf{2 0 1 1}$ & $\mathbf{4 5 , 2 \%}$ & $26,5 \%$ & $5,5 \%$ & $27,2 \%$ & $38,1 \%$ & $28,8 \%$ & $35,9 \%$ \\
$\mathbf{2 0 1 2}$ & $\mathbf{4 6 , 7 \%}$ & $28,8 \%$ & $6,2 \%$ & $26,9 \%$ & $39,4 \%$ & $28,5 \%$ & $36,6 \%$ \\
$\mathbf{2 0 1 3}$ & $\mathbf{4 7 , 1 \%}$ & $31,8 \%$ & $6,7 \%$ & $25,4 \%$ & $40,6 \%$ & $29,5 \%$ & $37,1 \%$ \\
$\mathbf{2 0 1 4}$ & $\mathbf{4 7 , 6 \%}$ & $37,1 \%$ & $8,8 \%$ & $25,6 \%$ & $42,3 \%$ & $29,4 \%$ & $37,6 \%$ \\
$\mathbf{2 0 1 5}$ & $\mathbf{4 9 , 2 \%}$ & $37,4 \%$ & $12,3 \%$ & $27,1 \%$ & $43,2 \%$ & $31,2 \%$ & $39,6 \%$ \\
\hline
\end{tabular}

Continuation of the table 1.

\begin{tabular}{cccccccc}
\hline Years & Malta & Poland & Slovakia & Slovenia & Bulgaria & Romania & Croatia \\
\hline $\mathbf{2 0 0 5}$ & $28,0 \%$ & $40,7 \%$ & $46,0 \%$ & $25,4 \%$ & $59,2 \%$ & $48,9 \%$ & $29,5 \%$ \\
$\mathbf{2 0 0 6}$ & $25,1 \%$ & $39,1 \%$ & $42,5 \%$ & $24,3 \%$ & $56,2 \%$ & $45,4 \%$ & $29,1 \%$ \\
$\mathbf{2 0 0 7}$ & $25,5 \%$ & $39,3 \%$ & $36,7 \%$ & $22,3 \%$ & $54,2 \%$ & $39,4 \%$ & $29,5 \%$ \\
$\mathbf{2 0 0 8}$ & $22,6 \%$ & $32,6 \%$ & $30,8 \%$ & $19,0 \%$ & $49,9 \%$ & $40,9 \%$ & $26,8 \%$ \\
$\mathbf{2 0 0 9}$ & $20,4 \%$ & $42,9 \%$ & $27,5 \%$ & $13,4 \%$ & $47,0 \%$ & $45,9 \%$ & $26,1 \%$ \\
$\mathbf{2 0 1 0}$ & $22,0 \%$ & $40,4 \%$ & $30,6 \%$ & $14,7 \%$ & $48,0 \%$ & $46,3 \%$ & $26,6 \%$ \\
$\mathbf{2 0 1 1}$ & $20,8 \%$ & $42,3 \%$ & $30,0 \%$ & $15,6 \%$ & $48,9 \%$ & $46,0 \%$ & $28,5 \%$ \\
$\mathbf{2 0 1 2}$ & $21,2 \%$ & $44,3 \%$ & $30,4 \%$ & $17,2 \%$ & $49,9 \%$ & $48,7 \%$ & $31,2 \%$ \\
$\mathbf{2 0 1 3}$ & $18,6 \%$ & $44,3 \%$ & $31,4 \%$ & $16,9 \%$ & $50,6 \%$ & $46,8 \%$ & $31,9 \%$ \\
$\mathbf{2 0 1 4}$ & $19,2 \%$ & $44,2 \%$ & $32,2 \%$ & $18,7 \%$ & $52,0 \%$ & $47,3 \%$ & $34,0 \%$ \\
$\mathbf{2 0 1 5}$ & $19,8 \%$ & $45,8 \%$ & $33,8 \%$ & $20,5 \%$ & $53,1 \%$ & $48,9 \%$ & $35,1 \%$ \\
\hline
\end{tabular}

Source: Authors' calculations based on Eurostat data

The analysis of the coefficient of variation of prices of the "new members" in relation to the EU-28 average shows that in the years following the accession to the EU there was a decrease in the coefficient of variation of prices and that means that the sigma convergence of prices is present.This means that membership in the EU, in the event that the country has a lower price level than the EU average before membership, inevitably leads to a increase in prices or a reduction in the dispersion of prices, but that in years after membership there may also be divergent movements, as in the case of Poland and Hungary.In Croatia, after the membership, there was a decrease in the price level in relation to the EU-28 average, which is the result of a lower degree of trade integration with the EU com- pared to other member states, and an increase in price levels can be expected with joining the monetary union, which is best seen on the example of Slovenia, whose coefficient of variation of prices at the beginning of the observed period in 2005 was $25.4 \%$, and at the end of the period, $20.5 \%$, despite the divergent trends since 2009. Given that the price level in Bosnia and Herzegovina is currently at about $50 \%$ of the EU28 level, it is expected that, as a result of the activation of the Stabilization and Association Agreement of Bosnia and Herzegovina with the EU, and a higher degree of trade integration, prices will increase and the coefficient of variation will decrease, because of all the countries observed in the previous table, Bosnia and Herzegovina has the lowest price level. 
Chart 3 shows the movement of the price level of Bosnia and Herzegovina in relation to the EU-28 average. The specified analysis shows that in the period from 2005-2009, sigma convergence of the price level of Bosnia and Herzegovina in relation to the EU-28 average was realized, but since 2009 there have been divergent trends, as is the case with Slovenia.Divergent price movements were mainly caused by a price drop of petroleum products and food products, but also by a higher absolute growth of GDP p.c. EU - 28 in relation to countries where price drops are present. It is to be expected that the price level in Bosnia and Herzegovina will increase in the coming period, given the high degree of trade integration with the EU-28 (71.8\% participation in Bosnia and Herzegovina exports, and $60.85 \%$ in Bosnia and Herzegovina imports) ${ }^{4}$.

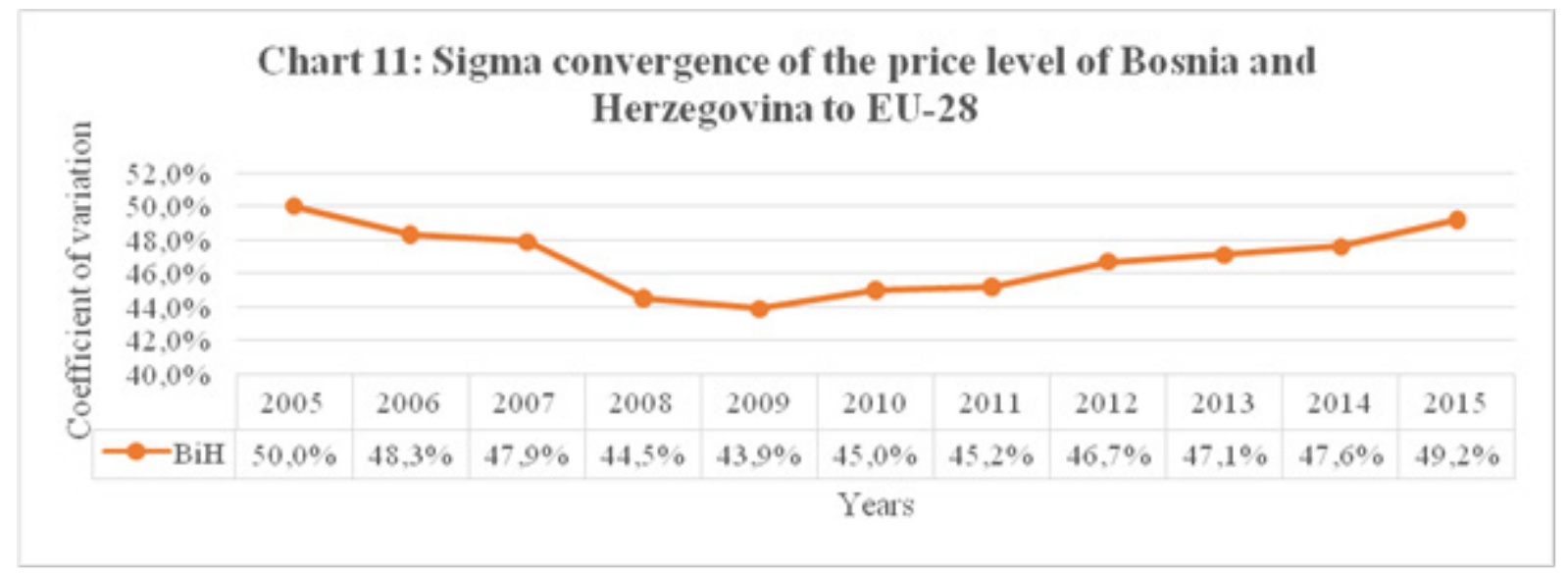

Source: Authors' calculations based on Eurostat data

The lack of data in the Eurostat reports for a comparative overview of prices by activities of Bosnia and Herzegovina in relation to the price level by activities at the EU28 level is a limitation of a more detailed analysis of the pressure on price increase for certain activities.It remains to be hoped that in the forthcoming period, Eurostat reports will also include price analysis by activities in Bosnia and Herzegovina, so that an assessment of the impact on price increase by product groups can be made after the integration of Bosnia and Herzegovina into the EU.

One of the criteria of real convergence is also the balance of the real exchange rate. Since Bosnia and Herzegovina has fixed its currency to the Euro, it means accepting the policy of the ECB, which ensures the balance of the real exchange rate $\mathrm{KM} \longleftrightarrow$ Euro.

\section{CONCLUSION}

In total, Bosnia and Herzegovina, by virtue of all the criteria of real convergence, except from the balance of the real exchange rate, is far from the real convergence to the average of economic parameters at the EU-28 level. There is a sigma convergence only in per capita income, but there is an increase in the absolute GDP p.c. gap ,which means the absence of real convergence, due to the low rate of economic growth. Due to significant deviation of the GDP p.c. compared to the EU-28 average, it is certain that GDP p.c will grow, and that the coefficient of variation of per capita income will reduce, currently at
$85.3 \%$, but due to the limited availability of capital and the concentration of low-cumulative economic branches and the underdevelopment of capital markets, income convergence will take a long time, and the question is whether it will ever fully accomplish. There is sigma divergence in the level of productivity, as well as divergent movements in the price level of Bosnia and Herzegovina in relation to the EU-28 average. It is imminent that as a consequence of the continuous increase in trade integration with the EU, prices will increase, which, in the absence of an increase in the rate of economic growth, could, primarily, negatively affect the standard of living in Bosnia and Herzegovina.Based on that, Bosnia and Herzegovina must make efforts to meet the criteria of nominal convergence, first of all, to establish a functioning market economy, but also to create an adequate business environment in order to improve its position in the competitiveness reports of international financial institutions, and thus, with a higher degree of political stability, directly influence the increase in both domestic and foreign direct investments, which through technology transfer would have a direct impact on the level of productivity of the labor force, and ultimately directly accelerating the real convergence of Bosnia and Herzegovina towards the EU.

${ }^{4}$ According to: http://www.mvteo.gov.ba/izvjestaji_publikacije/izvjestaji/default.aspx?id=7897\&langTag=bs-BA (accessed 11.7.2017.) 
It is especially important to emphasize that a systemic approach at the state level is needed to meet the economic criteria of convergence, which will result in concrete measures and activities, which will then be implemented vertically at lower levels of government.Otherwise, the problems of achieving political consensus on the European path of Bosnia and Herzegovina, ignoring the economic criteria of convergence, can result in negative effects of integration, which certainly should not be the aim of Bosnia and Herzegovina.It is also necessary to complete the transition of the business system in order to provide a functioning market economy and create the preconditions for the growth of the competitiveness of the economy of Bosnia and Herzegovina in the European environment.

\section{REFERENCES}

Bilas, V. (2005). Convergence of Transition Countries to the European Union. Economic Review, 56 (3-4). P. 221-238.

Gaspar, P. (2001). Real and Nominal Convergence of Pre-Accession Economies and the Choice of Exchange Rate Regime. International Centre for Economic Growth (ICEG) and Budapest University of Economics (BUE). Paper presented on the conference Alternatives for Exchange Rate Regime in Pre-Accession Economies. Vienna. September 20-21.

Hallet, M. (2002). Regional specialisation and concentration in the EU. Berlin. Springer.

http://bhas.ba/saopstenja/2016/GDP\%20Proizvodni2015.pdf

http://www.ec.europa.eu/eurostat/

http://www.data.worldbank.org

https://data.oecd.org

http://www.mvteo.gov.ba/izvjestaji_publikacije/izvjestaji/default.aspx?id $=7897$ \&langTag $=b s-B A$

Marelli, E. (2007). Specialisation and convergence of European regions. The European Journal of Comparative Economics, Vol. 4, n. 2. str. 149. - 178. 